\title{
INFLUÊNCIA DO CICLO POLÍTICO NA ARRECADAÇÃO DA CONTRIBUIÇÃO DE MELHORIA
}

\section{INFLUENCE OF POLITICAL CYCLE ON BETTERMENT TAX OF COLLECTION}

Wellington de Oliveira Massardi *

Professor da Faculdade Governador Ozanam Coelho - FAGOC.

Ubá, MG, Brasil

E-mail: wellingtonmassardi@hotmail.com

Andiara de Jesus Braga

Faculdade Governador Ozanam Coelho - FAGOC.

Ubá, MG, Brasil

E-mail: andiaradejesus@yahoo.com.br

João Paulo Ciribelli

Faculdade Governador Ozanam Coelho - FAGOC.

Ubá, MG, Brasil

E-mail: jpciri@hotmail.com

Joás Weslei Baia

Faculdade Governador Ozanam Coelho - FAGOC.

Ubá, MG, Brasil

E-mail: joasweslei@gmail.com

\section{RESUMO}

A presente pesquisa teve por objetivo analisar a influência do ciclo político na arrecadação da contribuição de melhoria, que é um tributo incidente sobre a valorização imobiliária provocada pela realização de uma obra pública. A teoria do ciclo político refere-se ao comportamento, em períodos eleitorais, dos gestores públicos que buscam uma reeleição e por isso aumentam as despesas públicas e diminuem a pressão tributária sobre os contribuintes. Para atender a esse objetivo, foi desenvolvido um modelo de regressão com dados em painel, com a inclusão de variáveis dummies para captar a influência do calendário eleitoral na arrecadação do tributo no período de 2004 a 2012. Os resultados indicaram que, nos municípios que compõem a amostra, não há influência do período eleitoral na arrecadação da contribuição, uma vez que a influência política está relacionada com a não aplicabilidade do tributo.

Palavras-chave: Arrecadação. Contribuição de Melhoria. Teoria do Ciclo Político-Econômico.

\section{ABSTRACT}

The present study aimed to analyze the influence of the political cycle in the tax revenue of Betterment Tax, which is a tax on real estate valuation caused by the completion of a public work. The theory of the policy cycle refers to behavior in election periods, public managers seeking re-election and therefore increase public spending and reduce the tax burden on taxpayers. To meet this goal, we developed a regression model with panel data, with the inclusion of dummy variables to capture the influence of the electoral calendar in the collection of the tax from 2004 to 2012. The results indicated that, in the municipalities that make up the sample, there is no influence of the electoral period in the collection of contributions, since the political influence is related to the non-applicability of the tax.

Keywords: Tax Revenue. Betterment Tax. Theory of Political and Economic Cycle.

Data de aprovação: 20 de julho de 2016.

Data de submissão: 12 de outubro de 2015. 


\section{INTRODUÇÃO}

A contribuição de melhoria é um tributo de competência comum a todos os entes tributantes - a União, os Estados e os Municípios - que tem como fato gerador a valorização de imóveis em uma região beneficiada por uma obra pública. Sendo assim, o ente responsável pela realização da obra pode cobrar a contribuição como forma de financiamento da obra, desde que essa cobrança não seja superior à valorização do imóvel (LEONETTI, 1998; GOMIDE, 2009; MASSARDI et al., 2014).

Basicamente, a contribuição de melhoria é um tributo cujo objetivo é recuperar o montante de recursos públicos investidos em obras públicas que provocaram valorização de imóveis particulares. Esse tributo está intimamente relacionado à noção de justiça fiscal, uma vez que não é função do poder público promover o enriquecimento de particulares; além disso, representa uma forma alternativa de financiamento de obras públicas.

Massardi et al. (2014), demonstraram a importância financeira da Contribuição de Melhoria para os municípios brasileiros como uma fonte alternativa de arrecadação, sendo constatado que os municípios que arrecadaram a Contribuição de Melhoria apresentaram situação financeira melhor em relação aos demais, com maiores índices de liquidez e com menor grau de endividamento.

Mesmo diante dos benefícios, a contribuição de melhoria ainda é pouco conhecida e aplicada pelos gestores públicos, portanto não possui uma participação significativa na composição das receitas públicas, conforme pode ser verificado em estudos empíricos que evidenciaram a utilização efetiva da contribuição de melhoria (GOMIDE; FARONI, 2008; BALSANELLI, 2011; GOMIDE, 2009; MASSARDI et al., 2014).

Como motivos da não utilização da contribuição de melhoria, Gomide (2009) aponta o desconhecimento do tributo pelos gestores e a complexidade de sua aplicação. Contudo, ressalta a influência de questões políticas, pois a ideia de que a aplicação da contribuição de melhoria pode desagradar o eleitorado é constante na visão dos políticos.

De acordo com Tristão (2003), os gestores públicos buscam evitar o ônus político da imposição tributária, principalmente em pequenos municípios, que dependem em maior ou menor grau das transferências intergovernamentais, uma vez que o custo político de aumentar a arrecadação seria muito maior do que a vantagem política de aumentar as despesas.

Nesse contexto, é notória a influência do aspecto político nas finanças municipais, especialmente em períodos próximos às eleições, ocasião em que os governantes dificilmente tomariam atitudes que viessem a prejudicar sua imagem perante o eleitorado. Essa postura dos políticos acaba se transformando em um ciclo comportamental vicioso, evidenciado pela Teoria dos Ciclos Político-Econômicos.

Segundo essa teoria, o período eleitoral exerce uma grande influência na conduta dos gestores públicos que buscam alcançar uma reeleição ou a eleição de seu sucessor, e por isso acabam tomando algumas atitudes, como a elevação dos gastos públicos para o fornecimento de bens e serviços e a diminuição da carga tributária (SILVA, 2010).

$\mathrm{Na}$ literatura, existem vários estudos que analisaram a influência do ciclo político na postura dos governantes quanto às finanças públicas (NAGAKUMA, 2006; SAKURAI, 2005; SILVA, 2010; GOMIDE, 2009; MASSARDI et al., 2014). Entretanto, tais pesquisas têm como foco a análise da ampliação de gastos públicos 
em períodos eleitorais; assim, há uma carência de estudos que evidenciem o comportamento dos gestores em relação à diminuição da carga tributária para se reelegerem ou elegerem seu sucessor.

Considerando os aspectos introdutórios, este trabalho busca responder ao seguinte questionamento: existe influência política na aplicação da contribuição de melhoria em períodos eleitorais?

Nesse sentido, a presente pesquisa tem por objetivo analisar a influência do ciclo político-econômico sobre a arrecadação da contribuição de melhoria por parte dos gestores públicos municipais. Para atender a esse objetivo, foram criadas as seguintes hipóteses:

$\mathrm{H}_{0}$ - não existe influência do ciclo político na arrecadação da contribuição de melhoria; e

$\mathrm{H}_{1}$ - os municípios arrecadaram menos contribuição de melhoria em períodos eleitorais.

\section{REFERENCIAL TEÓRICO}

\section{Teoria do Ciclo Político-Econômico}

As primeiras manifestações teóricas que evidenciaram a influência do calendário eleitoral sobre o comportamento dos políticos foram os trabalhos de Kalecki (1943), Akerman (1947) e Downs (1957). Esses estudos apresentam modelos formais que explicam o impacto dos fatores políticos sobre a economia de um país e por isso diferem dos modelos econômicos tradicionais que utilizam apenas variáveis econômicas para explicar o comportamento cíclico da economia.

A partir dos anos da década de 70 , intensificaram-se as discussões sobre a influência do período eleitoral no comportamento dos políticos e seus reflexos na economia. Nesse contexto, surge a Teoria do Ciclo Político-Econômico, partindo do princípio de que os ciclos econômicos são influenciados, em parte, pela aproximação das eleições, considerando-se a postura dos gestores públicos perante as políticas econômicas e fiscais, com o intuito de criar um cenário favorável a sua permanência no poder (SILVA, 2010).

Entretanto, percebem-se algumas divergências entre os teóricos em relação aos verdadeiros motivos que levam os governantes a implementarem determinadas políticas públicas em desfavor de outras. O modelo sugerido por Nordhaus (1975) apresenta uma visão individualista por parte do gestor público, que age de maneira oportunista, visando sua permanência no poder; em contrapartida, o modelo apresentado por Hibbs (1977) afirma que a ação dos políticos tem uma ligação direta com sua ideologia partidária.

Além desses diferentes pontos de vista, a Teoria do Ciclo Político-econômico pode ser subdividida em duas abordagens distintas que se diferem em relação à formação da expectativa do eleitorado. Os primeiros estudos realizados por Nordhaus (1975) tinham como pressuposto a existência de um eleitor ingênuo, que baseava suas expectativas apenas em fatos passados; em virtude disso, é classificada na literatura como sendo uma abordagem tradicional. Posteriormente, Rogoff e Sibert (1988) introduziram uma nova forma de pensamento que apresenta o eleitor a partir de suas expectativas racionais, baseando suas escolhas em previsões futuras.

A Teoria dos Ciclos Político-Econômicos Tradicionais foi desenvolvida na década de 1970 e pode ser dividida em dois modelos diferentes: o Oportunista e o Partidário. O primeiro foi desenvolvido por Nordhaus (1975), o qual acredita que os governantes agem de maneira oportunista com a finalidade única e exclusiva 
de se manterem no poder. Já o modelo Partidário, apresentado por Hibbs (1977), sugere que os governantes agem de acordo com suas ideologias partidárias.

Ambos os modelos possuem uma visão comum em relação ao eleitor, pois sugerem que este age de maneira ingênua e toma suas decisões com base nas experiências passadas; além disso, possui uma memória curta em relação às políticas macroeconômicas. Esses dois modelos por serem os primeiros a serem desenvolvidos representam uma abordagem tradicional da teoria.

Posteriormente, na década de 1980, surge nesse contexto a Teoria dos Ciclos Político-Econômicos Racionais, que também é dividida em dois modelos: o Oportunista e o Partidário, desenvolvidos, respectivamente, por Rogoff e Sibert (1988) e por Alesina (1987). Nesses modelos, foi introduzida a visão de que os eleitores agem de maneira racional e tomam suas decisões baseando-se em informações econômicas tempestivas.

Dessa maneira, a literatura dos ciclos político-econômicos pode ser classificada conforme demonstrado no Quadro 1.

\begin{tabular}{|c|c|c|}
\multicolumn{2}{|c|}{ Quadro 1 - Classificação da literatura dos ciclos político-econômicos } \\
\hline CORRENTES & TRADICIONAL & RACIONAL \\
\hline Expectativas & Adaptativas & Racionais \\
\hline Políticos & Políticos oportunistas & Políticos ideológicos \\
\hline \multirow{2}{*}{ Modelos } & $\frac{\text { Oportunista tradicional }}{\text { Nordhaus (1975) }}$ & $\begin{array}{c}\text { Oportunista racional } \\
\text { Rogoff e Sibert (1988) }\end{array}$ \\
\cline { 2 - 4 } & $\frac{\text { Partidário tradicional }}{\text { Hibbs (1977) }}$ & $\frac{\text { Partidário racional }}{\text { Alesina (1987) }}$ \\
\hline
\end{tabular}

Fonte: Lima, 2010.

$\mathrm{Na}$ literatura estrangeira, existem diversos estudos empíricos sobre os ciclos político-econômicos, entretanto a grande maioria desses trabalhos se concentra nos agregados macroeconômicos, como taxa de inflação, desemprego e crescimento econômico e suas relações com as eleições em nível nacional.

No Brasil, os estudos sobre os ciclos políticos nas unidades subnacionais são recentes (COSSIO, 1995; FERREIRA, 2006; NAGAKUMA, 2006; SAKURAI, 2005; NAGAKUMA; BENDER, 2010; SILVA, 2010). Os trabalhos de Cossio (1995) e Nagakuma (2006) contemplam os estados brasileiros, enquanto que os estudos de Ferreira (2006), Silva (2010) e de Sakurai (2005) abordam, de forma específica, o caso das esferas municipais.

Cóssio (1998) analisou o comportamento fiscal dos estados brasileiros no período de 1985 a 1997, confrontando as despesas públicas com o nível de população e os partidos políticos dos gestores, bem como incluindo uma variável no modelo para mensurar a influência das alianças partidárias com os governantes das estâncias superiores e com os parlamentares das assembleias legislativas. Utilizando a metodologia de dados em painel, o autor identificou evidências da existência do ciclo político para as despesas estaduais em anos eleitorais.

O trabalho de Nagakuma (2006) buscou analisar o impacto da Emenda Constitucional da Reeleição e da Lei de Responsabilidade Fiscal sobre o ciclo político-orçamentário, assim como sobre a performance 
fiscal do estados brasileiros no período de 1986 a 2002. Ficou evidenciado que a primeira intensificou a influência das eleições sobre o comportamento oportunistas dos governantes.

Ferreira (2006) buscou analisar o efeito das transferências politicamente motivadas sobre os equilíbrios eleitorais e fiscais subnacionais através de uma extensão do modelo de Rogoff e Sibert (1988) e, secundariamente, introduziu o endividamento como fonte alternativa de financiamento público. Nesse estudo, ficou constatado que essas transferências podem eliminar o ciclo político-orçamentário, entretanto podem gerar um problema de seleção adversa, colocando no poder um titular incompetente.

No estudo de Sakurai (2005), objetivou-se demonstrar evidências de ciclos orçamentários racionais nos municípios paulistas no período de 1989 a 2001, através de modelos econométricos de dados em painel e de variável dependente binária (Probit e Logit). Os resultados indicaram impulsos positivos nas despesas orçamentárias em anos eleitorais; contudo, não foi verificada a evidência de racionalidade raciocínio dos eleitores nos mesmos moldes da teoria do ciclo eleitoreiro racional.

Silva (2010) buscou analisar o comportamento dos gastos públicos dos municípios mineiros entre os anos de 2000 a 2008 perante a influência dos anos eleitorais, utilizando uma abordagem econométrica de dados em painel. Os resultados evidenciaram a influência estatisticamente significativa do calendário eleitoral sobre as despesas orçamentárias desses municípios.

\section{Histórico da Contribuição de melhoria}

Segundo Pinto (1937) e Massardi et al. (2014), a contribuição de melhoria é um tributo que incide sobre a valorização imobiliária provocada pela realização de uma obra pública, seja ela realizada exclusiva ou concorrentemente pelo Município, Estado e União, a qual atende a dois critérios: o montante global do tributo arrecadado não deve ultrapassar o valor total da obra; e o contribuinte individual não deve pagar uma parcela maior que o benefício auferido pela valorização de seu imóvel.

A contribuição de melhoria existe há muitos anos, entretanto há discordância entre os doutrinadores sobre a sua verdadeira origem, apesar de existir um consenso na doutrina no que diz respeito à contribuição de melhoria como obrigação financeira no modelo atual (LEONETTI, 1998). Sua primeira manifestação teria ocorrido na Europa, no século XIII, onde foi utilizada para o financiamento da construção de diques no rio Tâmisa, na Inglaterra, e para o embelezamento das praças de Florença na Itália (SILVA, 1995).

De acordo com Leonetti (1998), no Brasil, somente em 1812 aconteceu a primeira cobrança de tributos no mesmo modelo que a contribuição de melhoria, sendo que essa cobrança aconteceu na Bahia. Já em 1825, publicou-se a primeira lei que designava quanto deveria ser subtraído do montante da valorização imobiliária a ser pago na desapropriação de imóveis. A primeira constituição a analisar expressamente qual a possibilidade de se instituir a contribuição de melhoria foi a Constituição Brasileira de 1934. Desde essa data, a contribuição de melhoria sofreu várias mudanças até chegar à forma como se apresenta nos dias atuais.

O tributo tem como objetivo a recuperação do montante de recursos públicos aplicados em obras que provocaram a valorização de imóveis não públicos. O estudo de Biava (1978) mostra que, em outros países, esse tributo é de grande importância financeira, demonstrando sua viabilidade tributária. Afirma também que a utilização da contribuição de melhoria pode fazer com que o Sistema Tributário Nacional seja mais estável 
e justo, reduzindo o efeito da especulação imobiliária; entretanto, não é efetivamente cobrada mediante falsos pretextos sob a inviabilidade técnica e econômica (BIAVA, 1978).

De acordo com Rocha (2005), a aplicação da cobrança é difícil, uma vez que o poder público tem dificuldade em mensurar a valorização imobiliária causada pela obra pública. Contudo, a não aplicação do tributo pelos gestores públicos está em desacordo com os princípios da Lei da Responsabilidade Fiscal, que estabelece em seu Art. 14 a vedação da renúncia de receitas.

\section{A contribuição de melhoria como espécie tributária própria}

Machado (2010) alerta que, apesar de ser diferente da taxa e do imposto - e mesmo que existam algumas manifestações doutrinárias contra esse pensamento -, a contribuição de melhoria é tratada como uma espécie de tributo. $O$ sistema tributário brasileiro define a contribuição de melhoria como uma espécie tributária distinta, portanto prevalece a corrente doutrinária que afirma isso.

Conforme descrito no Art. $3^{\circ}$ da Lei $n^{\circ} 5.172 / 66$ que instituiu o CTN, os impostos, as taxas e as contribuições de melhoria possuem características comuns, no entanto existem algumas diferenciações que os tornam espécies diferentes de tributos (BRASIL, 1966).

O Art. 16 do CTN afirma que imposto é o tributo cujo valor financeiro é exigido pelo poder público a fim de atender as despesas realizadas para o interesse comum, não levando em consideração as vantagens de ordem pessoal ou particular (BRASIL, 1966).

Segundo o Art. 77 do CTN (BRASIL, 1966), a taxa é uma espécie tributária na qual se exige uma atuação estatal direta para o contribuinte, exercendo o "Poder de Polícia" e utilizando o serviço público efetiva ou potencialmente à disposição do contribuinte. Gomide (2009) esclarece a diferença entre taxa e contribuição de melhoria: a primeira refere-se à prestação de um serviço público; já a segunda origina-se na ocorrência de valorização imobiliária provocada por uma obra pública.

O Quadro 2 possibilita fazer a distinção entre a natureza jurídica da contribuição de melhoria e das demais espécies tributárias, incluindo os empréstimos compulsórios e as contribuições sociais. 
Quadro 2 - Distinção das espécies tributárias

\begin{tabular}{|c|c|}
\hline CONTRIBUIÇÃO DE MELHORIA & IMPOSTOS \\
\hline $\begin{array}{c}\text { Está relacionada com atividade do Poder Público } \\
\text { específico ao contribuinte - realização de obra pública. }\end{array}$ & $\begin{array}{c}\text { É cobrado independentemente de atuação } \\
\text { estatal específica ao contribuinte. }\end{array}$ \\
\hline CONTRIBUIÇÃO DE MELHORIA & TAXA \\
\hline $\begin{array}{c}\text { Tem como fato gerador o benefício advindo ao imóvel, } \\
\text { em consequência de obra pública. }\end{array}$ & $\begin{array}{c}\text { Fato gerador é o serviço público específico e } \\
\text { divisivel, posto à disposição do contribuinte ou } \\
\text { ao exercício do poder de polícia. }\end{array}$ \\
\hline CONTRIBUIÇÃO DE MELHORIA & EMPRÉSTIMO COMPULSÓRIO \\
\hline A restituição não é prevista. & $\begin{array}{c}\text { Há restituição ao contribuinte do montante pago } \\
\text { no empréstimo. }\end{array}$ \\
\hline CONTRIBUIÇÁO DE MELHORIA & CONTRIBUIÇÕES SOCIAIS \\
\hline $\begin{array}{c}\text { Destina-se ao custeio de obras públicas que tragam } \\
\text { beneficio imobiliário para o contribuinte. }\end{array}$ & $\begin{array}{c}\text { Instrumentos de intervenção no domínio } \\
\text { econômico ou de instituição nos interesses das } \\
\text { categorias profissionais ou econômicas. }\end{array}$ \\
\hline
\end{tabular}

Fonte: Gomide (2009).

\section{Aspectos legais da contribuição de melhoria}

A contribuição de melhoria é um tributo previsto na Constituição Federal de 1988 em seu Art. 145, inciso III (BRASIL, 1988), o qual estipulou que esse tributo seria de competência comum a todos os entes tributantes, sejam os Estados, Municípios e a União. A contribuição de melhoria é disciplinada ainda pelo CTN em seus artigos 81 e 82, e pelo Decreto-Lei 195/67, que foi recepcionado pela atual Constituição Brasileira e, por isso, ainda se encontra em vigor (BRASIL, 1967).

O fator gerador da contribuição de melhoria é a valorização imobiliária de imóveis pertencentes a contribuintes, decorrente de uma obra pública, segundo o estabelecido pelo Art. $1^{\circ}$ do Decreto-Lei n 195/67: "A Contribuição de Melhoria, prevista na Constituição Federal tem como fato gerador o acréscimo do valor do imóvel localizado nas áreas beneficiadas direta ou indiretamente por obras públicas" (BRASIL, 1967).

No Art. $2^{\circ}$ do mesmo diploma legal, estão descritos os tipos de obras públicas que ensejarão a cobrança da contribuição de melhoria, que vão desde a abertura, o alargamento e a pavimentação de ruas, até a construção de aeródromos e aeroportos. De acordo com Machado (2010), as obras que não se inserirem em uma dessas situações não podem ser alvo da cobrança do tributo; no entanto, a descrição do artigo é de grande abrangência, o que torna muito difícil a possibilidade de existir alguma obra que não se enquadre nos requisitos do artigo.

A base de cálculo da contribuição de melhoria pode variar segundo o critério utilizado. Adotando-se o critério de valorização imobiliária, deve-se levar em consideração o quantum de valorização que o imóvel sofre em razão da obra pública; já pelo critério de custo, verifica-se o total das despesas da obra atribuída a cada imóvel (GOMIDE, 2009).

De acordo com o parágrafo $2^{\circ}$ do Art. $3^{\circ}$ do Decreto-Lei n¹95/67 (BRASIL, 1967), a base de cálculo da contribuição de melhoria é o custo da obra, seja ele parcial ou total. Leonetti (1998) diz que existe uma jurisprudência do Supremo Tribunal Federal quanto à base de cálculo da contribuição de melhoria. Essa base 
de cálculo é o próprio montante da mais-valia imobiliária apurada entre a diferença do valor de mercado antes e depois da obra, sendo que o limite individual da exação é o quantum da valorização do imóvel.

Outro aspecto que deve ser lembrado é a existência de um limite global do custo das obras, incorporando-se as despesas para sua execução, conforme determinado no Art. $4^{\circ}$ do Decreto-Lei n¹95/67 (BRASIL, 1967).

Em sua obra, Gomide (2009) descreve uma fórmula que serve para a aplicação e determinação da base de cálculo para a contribuição de melhoria: a contribuição relativa a cada imóvel será determinada pelo rateio da parcela do custo da obra a que se refere a alínea c, do inciso I do Art. 82 do CTN, pelos imóveis situados na zona beneficiada, em função dos respectivos fatores individuais de valorização.

A fórmula que explica a base de cálculo para a contribuição de melhoria, de acordo com Gomide (2009), está descrita abaixo:

$$
c m=\frac{c o \times v i}{\sum v i}
$$

Em que, $\mathrm{cm}$ representa o valor da contribuição de melhoria; co corresponde ao custo total da obra e vi a valorização individual de cada imóvel.

\section{METODOLOGIA}

A metodologia adotada tem uma abordagem predominantemente quantitativa, a qual se fundamenta principalmente em análises estatísticas, permitindo que se estabeleçam inferências sobre os resultados. Quanto aos fins, trata-se de uma pesquisa descritiva, por expor as características de determinado fenômeno sem, no entanto, ter o compromisso de explicá-lo, embora sirva de base para a explicação (VERGARA, 2005).

O estudo utilizou dados secundários oriundos do banco de dados sobre finanças do Brasil (FINBRA), disponível no site do Tesouro Nacional, que é fonte oficial utilizada em pesquisas na área de Ciências Sociais Aplicadas.

O período de análise compreende os anos de 2004 a 2012, abrangendo três eleições municipais, realizadas no ano de 2004, 2008 e 2012. A amostra do estudo compõe-se de 304 municípios que arrecadaram contribuição de melhoria em todos os anos pesquisados.

Para analisar a influência do calendário eleitoral sobre a arrecadação da contribuição de melhoria, a presente pesquisa fez uso da regressão múltipla com dados em painel, por ser o modelo mais utilizado na literatura para analisar a influência do ciclo eleitoral sobre a política fiscal do governo (COSSIO, 1995; FERREIRA, 2006; NAGAKUMA, 2006; SAKURAI, 2005; NAGAKUMA; BENDER, 2010; SILVA, 2010).

Silva e Júnior (2004) reforçam que o método de dados em painel apresenta inúmeras vantagens em relação aos métodos de série temporal e de corte transversal. Uma dessas vantagens é a redução do problema de colinearidade entre as variáveis explicativas, uma vez que permite um maior número de observações na análise, o que, consequentemente, aumenta os graus de liberdade e de eficiência dos parâmetros estimados. 
De acordo com Souza (2007), os principais modelos de dados que combinam uma série temporal e dados em corte transversal são: modelos de equações aparentemente não relacionadas (SUR); modelo com variável dummy ou de efeitos fixos; e modelo de efeitos aleatórios.

Segundo Silva e Júnior (2004), considerando N seções cruzadas, T observações de série temporal e $(k-1)$ variáveis explicativas, um modelo de dados em painel pode ser descrito através da seguinte fórmula:

$$
Y_{i t}=\beta_{1 i t}+\sum_{K=2}^{K} \beta_{K i t} X_{K i t}+e_{i t}
$$

Em que $Y_{i t}$ refere-se à variável dependente; $\beta_{1 i t}$ representa o intercepto diferenciado para cada unidade de seção cruzada $i$ no período $t ; X_{K i t}$ representa as variáveis independentes; $\beta_{K i t}$ corresponde às diferentes inclinações para cada unidade da seção cruzada $i$ no período $t$; e $e_{i t}$ é um termo de erro definido da mesma forma.

Para realizar o modelo de regressão foi selecionada uma variável dependente e múltiplas variáveis independentes, cujas expectativas teóricas estão descritas no Quadro 3.

Quadro 3 - Descrição das variáveis utilizadas no modelo

\begin{tabular}{|c|l|l|}
\hline Variável & \multicolumn{1}{|c|}{ Descrição } & \multicolumn{1}{|c|}{ Sinal esperado } \\
cmep & $\begin{array}{l}\text { Variável dependente. Representa o valor } \\
\text { per capita arrecadado referente ao } \\
\text { tributo contribuição de melhoria. }\end{array}$ & Não se aplica. \\
\hline rtrp & $\begin{array}{l}\text { Receita tributária do município per } \\
\text { capita. Compreende a arrecadação de } \\
\text { todos os tributos de competência } \\
\text { municipal, incluindo-se as taxas e a } \\
\text { contribuição de melhoria. }\end{array}$ & $\begin{array}{l}\text { Positivo, pois se subentende que, quanto maior a } \\
\text { arrecadação tributária, maior será a organização da } \\
\text { administração fazendária, consequentemente maior } \\
\text { será a arrecadação da contribuição de melhoria. }\end{array}$ \\
\hline doip & $\begin{array}{l}\text { Despesas per capita empenhadas com a } \\
\text { realização de obras e instalações. }\end{array}$ & $\begin{array}{l}\text { Positivo, pois, quanto maior for o investimento em } \\
\text { obras, maior será a possibilidade de arrecadação da } \\
\text { contribuição de melhoria. }\end{array}$ \\
\hline fpmp & $\begin{array}{l}\text { Representa o valor per capita recebido } \\
\text { pelo município referente ao Fundo de } \\
\text { Participação do Município (FPM). }\end{array}$ & $\begin{array}{l}\text { Negativo, pois a literatura indica que as receitas de } \\
\text { transferências do FPM provocam preguiça fiscal } \\
\text { diminuindo o esforço de arrecadação dos } \\
\text { municípios. }\end{array}$ \\
\hline pre & $\begin{array}{l}\text { Variável dummy que assume valor 1 para } \\
\text { os anos que antecedem as eleições } \\
\text { (2003, 2007 e 2011) e 0 para os demais } \\
\text { anos. }\end{array}$ & $\begin{array}{l}\text { Negativo, pois a teoria do ciclo-político eleitoral } \\
\text { indica que, próximo às eleições, há uma tendência } \\
\text { de elevação dos gastos públicos e redução da } \\
\text { arrecadação tributária. }\end{array}$ \\
\hline ele & $\begin{array}{l}\text { Variável dummy que assume valor 1 para } \\
\text { os anos eleitorais (2004, 2008 e 2012) e } \\
\text { 0 para os demais anos. }\end{array}$ & $\begin{array}{l}\text { Negativo, pois a teoria do ciclo-político eleitoral } \\
\text { indica que, em anos eleitorais, há uma tendência de } \\
\text { elevação dos gastos públicos e redução da } \\
\text { arrecadação tributária. }\end{array}$ \\
\hline pos & $\begin{array}{l}\text { Variável dummy que assume valor 1 para } \\
\text { os anos pós-eleitorais (2005, 2006 e } \\
2009)\end{array}$ & $\begin{array}{l}\text { Positivo, pois logo após as eleições espera-se que } \\
\text { haja um aumento da pressão tributária sobre os } \\
\text { contribuintes. }\end{array}$ \\
\hline
\end{tabular}

Fonte: Elaborado pelos autores

Como forma de padronização, todas as variáveis foram transformadas em logaritmo natural, sendo especificada a fórmula funcional para o modelo log-log, por se tratar, segundo Gujarati (2006), de uma medida de sensibilidade que demonstra a relação percentual entre a variável dependente e as explicativas. Sendo 
assim, para demonstrar evidências da influência do calendário eleitoral sobre a arrecadação da contribuição de melhoria pelos municípios brasileiros no período de 2004 a 2012, propõe-se a seguinte fórmula funcional:

$$
\begin{gathered}
\ln (\text { cmep })_{i t}=\beta_{0}+\beta_{1} \ln (r t r p)_{i t}+\beta_{2} \ln (\text { doip })_{i t}+\beta_{3} \ln (f p m p)_{i t}+\beta_{4} \text { pre }_{i t} \\
+\beta_{5} \text { ele }_{i t}+\beta_{5} \text { pos }_{i t}+U_{i t}
\end{gathered}
$$

Em que $\ln (\mathrm{cmep})_{i t}$ é o logaritmo natural da arrecadação per capita da contribuição de melhoria; $\beta_{0}$ é a constante; $\ln (r t r p)_{i t}$ é o logaritmo natural da receita tributária per capita; $\ln (\text { doip })_{i t}$ é o logaritmo natural da despesa com obras e instalações; $\ln (f p m p)_{i t}$ é o logaritmo natural do Fundo de Participação dos Municípios per capita;; pre $_{i t}$, ele $e_{i t}$ e pos $_{i t}$ são variáveis dummies que indicam respectivamente os anos préeleitoral, eleitoral e pós-eleitoral, assumindo valor 1 para os anos de interesse e 0 para os demais anos; $U_{i t}$ é o termo de erro estocástico.

Para realização do procedimento estatístico e estimação do modelo de dados em painel, utilizou-se o software STATA 12.0, sendo os resultados apresentados na seção seguinte.

\section{RESULTADOS E DISCUSSÕES}

Embora o objetivo do trabalho tenha priorizado uma análise predominantemente municipal, é possível e conveniente fazer uma verificação macrorregional da arrecadação de contribuição de melhoria, ou seja, identificar as regiões do Brasil com maior e menor arrecadação.

Com base nos dados, percebe-se que a região Sul apresenta a maior arrecadação, seguida das regiões Sudeste, Centro-Oeste, Norte e Nordeste. Ao todo, a região Sul possui 192 municípios, que arrecadaram a contribuição durante os anos de 2004 a 2012; a região Sudeste, 85 municípios; a CentroOeste, 23; e a Norte, 4. Não se encontrou, na região Nordeste, município que arrecade a contribuição em análise. A Tabela 1 discrimina as porcentagens de arrecadação por região.

Tabela 1 - Arrecadação da contribuição de melhoria pelas regiões brasileiras.

\begin{tabular}{ccrrr}
\hline \multirow{2}{*}{ REGIÃO } & \multicolumn{2}{c}{ NÚMERO DE MUNICÍPIOS } & \multicolumn{2}{c}{ ARRECADAÇÃO 2004 A 2012 } \\
\cline { 2 - 5 } & Valor absoluto & Valor relativo (\%) & \multicolumn{1}{c}{ Valor absoluto } & \multicolumn{1}{c}{ Valor relativo (\%) } \\
\hline Norte & 4 & $1,32 \%$ & $\mathrm{R} \$ 6.888 .480,58$ & $1,82 \%$ \\
Nordeste & 0 & $0,00 \%$ & & - \\
Sudeste & 85 & $27,96 \%$ & $\mathrm{R} \$ 120.663 .655,60$ & $31,64 \%$ \\
Sul & 192 & $63,16 \%$ & $\mathrm{R} \$ 168.552 .053,20$ & $44,19 \%$ \\
Centro-oeste & 23 & $7,57 \%$ & $\mathrm{R} \$ 85.286 .035,53$ & $22,36 \%$ \\
TOTAL & 304 & $100,00 \%$ & $\mathrm{R} \$ 381.390 .224,90$ & $100,00 \%$ \\
\hline
\end{tabular}

Fonte: dados da pesquisa

Quanto à análise dos 304 municípios, observou-se que estão localizados em 4 regiões da país e possuem de 1.521 habitantes (município de Montauri/RS) a 1.851.215 habitantes (município de Curitiba/PR). As estatísticas descritivas das variáveis utilizadas para a criação do modelo empírico utilizando dados em painel podem ser observadas na tabela abaixo. 
Tabela 2 - Estatísticas descritivas das variáveis

\begin{tabular}{crrrrrr}
\hline Variáveis & \multicolumn{1}{c}{ Mínimo } & \multicolumn{1}{c}{ Máximo } & \multicolumn{1}{c}{ Média } & Desvio padrão & Assimetria & Curtose \\
\hline CME & 0,01 & $9.111 .717,44$ & $139.397,01$ & $379.913,78$ & 13,05 & 253,07 \\
$\boldsymbol{R} T \boldsymbol{R}$ & $2.551,00$ & $1.688 .843 .224,73$ & $23.395 .146,53$ & $92.186 .783,04$ & 9,20 & 109,77 \\
DOI & $1.033,00$ & $449.317 .536,69$ & $8.706 .986,65$ & $25.249 .644,44$ & 8,38 & 100,12 \\
$\boldsymbol{P O P}$ & $1.521,00$ & $1.851 .215,00$ & $68.686,03$ & $168.668,74$ & 6,08 & 46,87 \\
$\boldsymbol{F P M}$ & $1.678 .809,86$ & $227.611 .085,01$ & $11.596 .679,09$ & $13.932 .940,24$ & 6,02 & 63,03 \\
\hline \multicolumn{7}{c}{ Fonte: dados da pesquisa. }
\end{tabular}

A média da Contribuição de Melhoria (CME) arrecadada nos 304 municípios foi de $R \$ 139.397,01$; e o município que menos arrecadou foi Franca/SP, no ano de 2007: $\mathrm{R} \$ 0,01$. O município que mais arrecadou foi o de Campo Grande/MS, com R\$9.111.717,44 no ano de 2011.

A Receita Tributária (RTR) média dos municípios analisados foi de $R \$ 23.395 .146,50$ sendo que, o município que apresentou a menor receita tributária foi o de Tijucas/SC em 2007 com R $\$ 2.551,00$ arrecadados, e o que apresentou maior arrecadação foi o município de Curitiba/PR em 2004 com $\mathrm{R} \$ 1.688 .843 .224,73$ arrecadados.

Em relação ao que o município arrecadou com o Fundo de Participação do Município (FPM), a média foi de $R \$ 11.596 .679,09$ arrecadados, sendo que o município que menos arrecadou foi o de Nova Bréscia/RS, em 2005 (R\$1.678.809,86), e o que mais obteve arrecadações foi o de Curitiba/PR, no ano de 2004 $(\mathrm{R} \$ 227.611 .085,00)$.

Primeiramente, buscou-se realizar os testes estatísticos para identificar o modelo mais adequado a ser utilizado. Os resultados dos testes, bem como o número de observações e o coeficiente de determinação da regressão $R^{2}$, estão descritos na Tabela 3.

Tabela 3 - Testes estatísticos para escolha do modelo e identificação de autocorrelação e heterocedasticidade

\begin{tabular}{cccccc}
\hline Observações & $\mathbf{R}^{\mathbf{2}}$ & Chow & Hausman & Wooldridge & Wald \\
\hline \multirow{2}{*}{2.736} & 0,134 & 303,24 & 112,75 & 56,454 & $2,1 \mathrm{e}^{+5}$ \\
& & $(0,000)$ & $(0,000)$ & $(0,000)$ & $(0,000)$ \\
\hline
\end{tabular}

Fonte: dados da pesquisa.

O teste de Chow foi realizado para verificar se o modelo de efeitos fixos é mais adequado do que o modelo pooled, sendo que o referido teste foi significativo em nível de $1 \%$ rejeitando a hipótese nula, o que indica que, nesse caso, o modelo de efeitos fixos é mais adequado do que o modelo pooled.

Em seguida, foi utilizado o teste de Hausman para fazer a comparação entre os modelos de efeito fixo e de efeito aleatório. O resultado do teste rejeitou a hipótese nula em nível de $1 \%$ de significância, constatando-se que o modelo de efeito fixo é mais adequado que o modelo de efeito aleatório, não sendo preciso, então, realizar o teste de Breush e Pagan de multiplicador de Lagrange (LM).

Após a identificação do modelo mais adequado, realizaram-se os testes de Wooldridge e de Wald para verificar a ausência de autocorrelação e heterocedasticidade, respectivamente. Os resultados dos testes indicaram a presença de heterocedasticidade e de autocorrelação, pois, em ambos, a hipótese nula foi rejeitada ao nível de significância de $1 \%$. A partir desse resultado, realizaram-se as correções por meio do procedimento Driscoll-Kraay. 
Os resultados do modelo corrigido estão descritos na Tabela 4, onde podem ser verificados os coeficientes das variáveis, bem como os erros-padrão e a significância estatística.

Tabela 4 - Estimativa de dados em painel para modelos de efeitos fixos corrigidos

\begin{tabular}{crrrrrr}
\hline Variáveis & Coeficiente & \multicolumn{1}{c}{ Erro padrão } & \multicolumn{1}{c}{$\mathbf{t}$} & \multicolumn{2}{c}{ P>t } & \multicolumn{2}{c}{$\begin{array}{c}\text { (Intervalo de Confiança } \\
\text { 95\%) }\end{array}$} \\
\hline Inrtrp & 1,04643 & 0,14374 & 7,28 & 0,000 & 0,76356 & 1,32929 \\
Infpmp & $-1,34049$ & 0,20452 & $-6,55$ & 0,000 & $-1,74295$ & $-0,93803$ \\
Indoip & 0,04383 & 0,07573 & 1,73 & 0,085 & $-0,01052$ & 0,16200 \\
pre & 0 (omitted) & & & & & \\
ele & $-0,12412$ & 0,11264 & $-1,10$ & 0,271 & $-0,34578$ & 0,09753 \\
pos & $-0,16566$ & 0,06793 & $-2,44$ & 0,015 & $-0,29935$ & $-0,03198$ \\
cons & 2,91666 & 0,82391 & 3,54 & 0,000 & 1,29534 & 4,53797 \\
\hline
\end{tabular}

Fonte: dados da pesquisa.

Primeiramente deve-se destacar que a variável pre - a qual se refere aos anos pré-eleitorais e, por isso, constitui-se em uma variável dummy - foi automaticamente omitida pelo Stata para evitar problemas de colinearidade provocados pela utilização extensa de variáveis dummies.

Para analisar os resultados, assumiu-se uma margem de erro de 0,10, pois, conforme afirmam Hair et al. (2005), o nível de erro estatístico depende do objetivo do pesquisador, podendo então assumir valores maiores; entretanto, o limite aceitável é de $10 \%$.

Dessa forma, verifica-se que somente a variável ele não foi estatisticamente significativa ( $p$-valor = $0,271>0,10$ ), ou seja, mesmo apresentando um coeficiente negativo, não se pode afirmar que há uma diminuição da arrecadação da contribuição de melhoria em anos eleitorais, conforme expectativa teórica do ciclo político eleitoral.

Considerando que os municípios que compõem a amostra arrecadaram a contribuição de melhoria em todos os anos analisados (2004 a 2012), pode-se inferir que a arrecadação do referido tributo ocorre de maneira institucionalizada nesses municípios e por isso não sofre influência do ciclo eleitoral; entretanto, desconsideraram-se os aspectos relacionados às reeleições que não foram mensurados.

Sendo assim, a influência política na arrecadação da contribuição pode ser confirmada pelo baixo número de municípios que aplicam o tributo em relação ao total de municípios do país, pois os governantes municipais, principalmente em pequenos municípios, preferem depender em maior grau das transferências intergovernamentais para evitar o ônus político da imposição tributária (GOMIDE, 2009; TRISTÃO, 2003).

Em períodos pós-eleitorais, verificou-se que há uma redução na arrecadação da contribuição de melhoria, que vai de encontro à pressuposição teórica de que há um aumento na pressão tributária. A justificativa para esse resultado está relacionada à característica própria do tributo, pois este incide sobre a realização de obras públicas, além de obedecer ao orçamento anual elaborado pela administração anterior.

De acordo com Silva (2010), as despesas públicas sofrem influência do ciclo político e tendem a aumentar em períodos próximos às eleições. Consequentemente, há um aumento na realização de obras públicas, que por sua vez são ínfimas nos períodos pós-eleitorais; dessa forma, diminui-se a base de cálculo para recolhimento da contribuição de melhoria. Ao analisar o coeficiente da variável Indoip, constatou-se que 
realmente há uma relação positiva entre as despesas com obras e instalações e a arrecadação da contribuição.

Em relação às variáveis Inrtrp e Infpmp, verificou-se uma relação positiva e negativa, respectivamente, com a arrecadação da contribuição de melhoria. Esses resultados confirmam a influência negativa do FPM no esforço de arrecadação dos municípios em relação aos tributos de sua competência, por exemplo, na própria contribuição. Em contrapartida, os municípios que possuem maior autonomia fiscal ao explorar sua base tributária própria possuem maior eficiência arrecadatória, e consequentemente são capazes de gerar maiores receitas de contribuições de melhoria.

\section{CONSIDERAÇÕES FINAIS}

O presente estudo procurou analisar a influência dos ciclos político-econômicos na arrecadação da contribuição de melhoria pelos gestores municipais. Constatou-se que, diferentemente do que a teoria do ciclo político afirmava e sabendo-se que esse tributo é de competência de todos os entes tributantes e está relacionado à noção de justiça fiscal, em anos de eleição não se pode afirmar que houve uma redução da arrecadação da contribuição de melhoria.

Vários estudos demonstram que o período eleitoral tem grande influência na postura dos governantes, pois estes buscam alcançar a reeleição ou eleição de seu sucessor elevando os gastos e reduzindo a carga tributária com vistas a proteger sua imagem. Nesse contexto, verificou-se que houve uma contraposição em relação a esse estudo, pois constatou-se que não há influência do ciclo político na arrecadação da contribuição de melhoria, uma vez que há aumento na arrecadação do tributo confirmando-se a hipótese H0. Esse aumento foi gerado uma vez que tal tributo está diretamente relacionado à realização de obras públicas, os quais diminuem em anos pós-eleições, obedecendo ao orçamento anual anterior.

Em relação às despesas, percebeu-se que elas impactam positivamente na arrecadação da contribuição, pois as obras públicas representam a própria base de cálculo do tributo. Em períodos próximos à eleição, há uma elevação na realização de obras públicas, entretanto a arrecadação da contribuição de melhoria nesse período não é estatisticamente significativa. Em períodos pós eleitorais verificou-se influência negativa na arrecadação da contribuição, isso devido à diminuição da realização de obras públicas.

Considerando que o estudo foi realizado apenas com os 304 municípios que arrecadaram a contribuição de melhoria em todos os anos, pode-se dizer que não sofreram influência do ciclo eleitoral, sugere-se que a arrecadação desse tributo nesses municípios ocorre de maneira institucionalizada, seguindo procedimentos pré-estabelecidos pelas diretrizes orçamentárias e legislações municipais específica, sofrendo, então, pouca influência das (re)eleições.

Contudo, a influência política pode ser observada pelo baixo número de municípios arrecadantes $(8,88 \%)$ do total de municípios do país, além disso, os valores arrecadados ainda são muito baixo quando comparados ao nível de investimentos em obras públicas. Além disso, os gestores dos pequenos municípios dependem das transferências governamentais para reduzir a carga tributária cobrada, gerando uma influência negativa dessas transferências no esforço de arrecadação da contribuição de melhoria. Sendo assim, municípios que possuem autonomia fiscal geram maiores receitas de contribuições de melhoria. Para pesquisas futuras, sugere-se a inclusão na amostra, municípios que arrecadaram a contribuição de melhoria 
em pelo menos um dos anos analisados para verificar se eles deixaram de arrecadar o tributo em períodos eleitorais.

\section{REFERÊNCIAS}

AKERMAN, J. Political Economic Cycles (1947), in B. S. FREY (ed.), Political Business Cycles. Coleção The International Library of Critical Writings in Economics. Cheltenham: Edward Elgar Publ. 1997.

ALESINA, A. Macroeconomic policy in a two party system as a repeated game. Quaterly Journal of Economics, v. 102, p. 651-678, 1987.

BALSANELLI, Adilson. Análise empírica da contribuição de melhoria nos municípios catarinenses no período de 2007 a 2009. Revista Catarinense de Ciência Contábil - CRCSC, Florianópolis, v. 10, n. 28, p. 59-71, dez./mar. 2011.

BIAVA, Adriano Henrique Rebelo. Contribuição de melhoria, um tributo esquecido. Revista de Administração Municipal, ano XXV, n. 148, p. 06-19, jul./ set. 1978.

BRASIL. Constituição da República Federativa do Brasil. Brasília, DF: Senado Federal, 1988.

. Lei 5.172, de 25 de outubro de 1966. Código tributário nacional. Dispõe sobre o Sistema tributário nacional e institui normas gerais de direito tributário aplicáveis à União, Estados e Municípios. Diário Oficial da União, Brasília, 1966.

. Decreto-lei $n^{\circ}$ 195, de 24 de fevereiro de 1967. Dispõe sobre a cobrança da Contribuição de Melhoria. Diário Oficial da União, Brasília, 1967.

COSSIO, F. A. B. Disparidades econômicas inter-regionais, capacidade de obtenção de recursos tributários, esforço fiscal e gasto público no federalismo brasileiro. Rio de Janeiro: PUC, 1995. Dissertação (Mestrado) - Pontifícia Universidade Católica, Rio de Janeiro, 1998.

DOWNS, Anthony. Economic Theory of Political Action in a Democracy. Journal of Political Economy, vol. 65, $\mathrm{n}^{\circ} 2$, abril, 1957.

FERREIRA, I. F. S. Eleições e política fiscal: o papel das transferências voluntárias intergovernamentais, da competência administrativa e do endividamento nos ciclos político-orçamentário. 2006. Tese (Doutorado em Economia) - Universidade de Brasília, DF.

FINBRA. Finanças do Brasil. Secretaria do Tesouro Nacional. Banco de dados finanças públicas. Disponível em: http://www.tesouro.fazenda.gov.br/pt_PT/contas-anuais. Acesso em: 12 jan. 2013.

GOMIDE, T. R. Aplicabilidade da contribuição de melhoria pela administração pública municipal. Minas Gerais: UFV, 2009. 114 f. Dissertação (Mestrado em Administração) Universidade Federal de Viçosa: Viçosa, 2009.

GOMIDE, T. R.; FARONI, W. Avaliação da arrecadação da contribuição de melhoria pelos municípios brasileiros. Revista de C. Humanas, v. 8, n. 1, p. 39-50, jan./jun. 2008.

GUJARATI, D. Econometria básica. 4. ed. Rio de Janeiro: Elsevier, 2006. 812 p.

HAIR, J. F.; BABIN, B.; MONEY, A. H.; SAMUEL, P. Fundamentos e métodos de pesquisa em administração. Trad. Lene Belon Ribeiro. Porto Alegre: Bookman, 2005. 471p.

HIBBS JR., Douglas A. Political parties and macroeconomic policy. American Political. 1977.

KALECKI, M. Political Aspects of Full Employment. Political Quarterly. Vol. 7, págs.

322-31. 1943

LEONETTI, C. A. A contribuição de melhoria na constituição de 1988. Santa Catarina: UFSC, 1998. 130 f. Dissertação (Mestrado em Direito) Universidade Federal de Santa Catarina, Florianópolis, 1998.

MACHADO, Hugo de Brito. Curso de direito tributário. 31. ed. São Paulo: Malheiros Editores, 2010.

MASSARDI et al. Impacto da contribuição de melhoria sobre a situação financeira dos municípios brasileiros. v. $5, \mathrm{n} .2$. Aparecida de Goiânia: UEG, 2014. 23 p.

NAKAGUMA, M.Y. Ciclos políticos e resultados eleitorais: um estudo sobre o comportamento do eleitor brasileiro. 2006. Dissertação (Mestrado em Economia) - Universidade do Estado de São Paulo, São Paulo, SP.

NAKAGUMA, M.Y.; BENDER, S. Ciclos políticos e resultados eleitorais: um estudo sobre o comportamento do eleitor brasileiro. RBE, Rio de Janeiro, v. 64, n. 1, p. 3-24. jan.- mar.2010.

NORDHAUS, W. D. The political business cycle. Review of Economic Studies, Bristal, England, v. 42, p. 169-190, 1975. 
PINTO, Olavo Bilac. Contribuição de melhoria. Rio de Janeiro: Forense, 1937.

ROCHA, João Marcelo. Direito Tributário. Rio de Janeiro: Ferreira, 2005.

ROGOFF, K.; SIBERT, A. Elections and macroeconomic policy cycles. The Review of Economic Studies, v. 55, n.1, p. 116, 1988.

SAKURAI, S. N. Testando a hipótese de ciclos eleitorais racionais nas eleições dos municípios paulistas. Estudos Econômicos, São Paulo, v. 35, n. 2, p. 297-315, 2005. Science Review, n. 71, p. 1467-14.

SILVA, Edgard Neves da. Contribuição de melhoria. In: SILVA, Ives Gandra da (Coord.). Curso de direito tributário. v. 2. 4. ed. Belém: CEJUP, 1995.

SILVA, O. M.; JÚNIOR, J. C. Dados em painel: uma análise do modelo estático. In: SANTOS; VIEIRA. Métodos quantitativos em economia. Viçosa: UFV, 2004.

SILVA, S. L. P. Ciclo político-orçamentário: um estudo em municípios do estado de Minas Gerais - 2000/2008. Viçosa, 2010.

SOUZA, C. O. Esforço fiscal e alocação de recursos nos municípios da zona da mata de Minas Gerais. Viçosa: UFV, 2007. Dissertação (Mestrado em Administração) - Universidade Federal de Viçosa, Viçosa, 2007.

TRISTÃO, José Américo Martelli. A administração tributária dos municípios brasileiros: uma avaliação do desempenho da arrecadação. São Paulo: EAESP/FGV, 2003. 172 f. Tese (Doutorado). Curso de Pós-Graduação da EAESP/FGV.

VERGARA, S. C. Projetos e relatórios de pesquisa em administração. São Paulo: Atlas, 2005 